\title{
ISOBIO: dynamic hygrothermal simulation and full-scale validation of a structural insulated panel made from bio-based materials
}

\author{
STYLE Oliver ${ }^{\text {a* }}$ \\ ${ }^{a}$ Praxis Resilient Buildings, C/Ramon Turro 100-104, 5-7, 08005 Barcelona, Spain.
}

\begin{abstract}
The article presents the results of ISOBIO, a European project that ran from 2015 to 2019, financed under the Horizon2020 program. The project developed new insulating materials and plasters from plant fibres, agricultural residues, and bio-based binders, with the aim of reducing both the embodied energy in the materials as well as operational energy consumption. The materials were incorporated into a prefabricated structural insulated panel, and installed and monitored in 2 demonstrators in the UK and Spain. The panel's hygrothermal performance was monitored and validated dynamically with a WUFI Pro model (to EN 15026 [1]), showing very reliable hygrothermal performance and a close correlation between modelled and measured values.
\end{abstract}

Peer-review under the responsibility of the organizing committee of the ICMB21.

Keywords: ISOBIO; H2020; hygrothermal modelling; bio-based materials; embodied energy; energy efficiency; thermal insulation; WUFI; EN 15026; ISO 6946; heat and moisture transfer; hemp; straw; clay; lime;

\section{ISOBIO structural insulated panel for new buildings}

The prototype panel measured $1.95 \mathrm{~m} \times 1.95 \mathrm{~m}$, with a total thickness of $33.2 \mathrm{~cm}$ in 8 layers with 9 different materials (Figure 1). The panel was rendered external with $25 \mathrm{~mm}$ of lime and hemp plaster, applied on a rigid $50 \mathrm{~mm}$ hemp insulation board, mechanically fixed to the $145 \mathrm{~mm}$ red pine wood structure filled with hemp, cotton, and flax insulation, followed by a $12 \mathrm{~mm}$ OSB 3 board. An airtight and dynamic vapour control membrane was fixed to the inner face of the OSB, followed by a $45 \mathrm{~mm}$ service void with hemp, cotton, and flax insulation, between timber battens, swing $90^{\circ}$ in relation to the main structural joists to reduce the thermal bridging through the timber. The inner service void was lined with a $40 \mathrm{~mm}$ thermo-compressed straw board, plastered on the inside with $15 \mathrm{~mm}$ of composite clay-hemp plaster, applied in 3 layers.
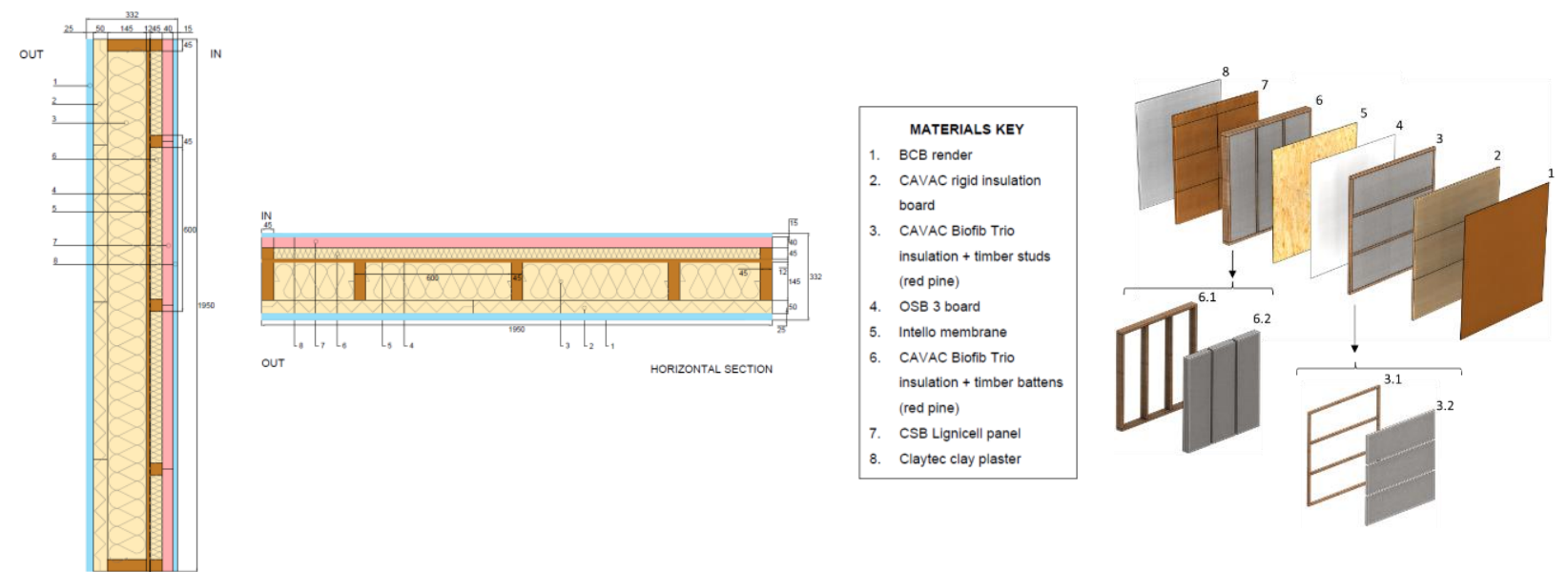

Figure 1: ISOBIO panel section drawings and materials
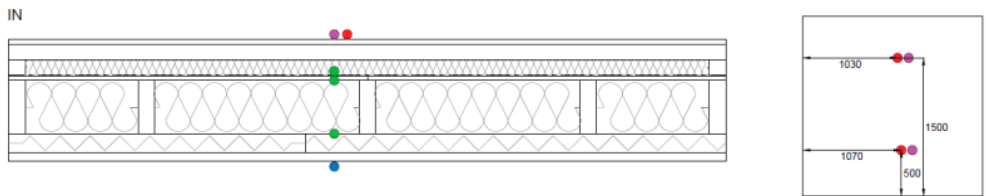

SENSORS KE

Heat Flow Meter

Interior surface temperature

Relative humidity \&

temperature

Exterior surface temperature

OUT

SENSOR INSTALLATION

Figure 2: Location and type of sensors installed in the panel

\footnotetext{
${ }^{*}$ Corresponding author. 0034600092 809. oliver@ praxis-rb.com
} 


\section{Test set-up}

A monitoring system was installed with a meteorological station recording the external conditions, with a temperature sensor on the outside face of the panel, a heat flow and temperature sensor on the inner face, in accordance with ISO 9869 [1]. In addition, temperature and relative humidity sensors were installed at 3 positions within the panel (Figure 2), to measure the transient hygrothermal behaviour inside the panel and compare the results with the WUFI model, according to EN 15026 [2]. The data was measured at an interval of 5 minutes. The interior temperature was maintained at an average temperature of $25.5^{\circ} \mathrm{C}$ throughout the period, with an electric air heater.

\section{Monitoring Results and Validation}

Figure 3 shows measured and modelled temperature and RH at position 2 (between the CAVAC rigid insulation and Biofib Trio insulation). Figure 4 shows the measured and modelled temperature at position 3 (between the Biofib Trio insulation and OSB board). Figure 5 shows the measured and modelled temperature and $\mathrm{RH}$ at position 4 (between the Intello membrane and the Biofib Trio insulation).

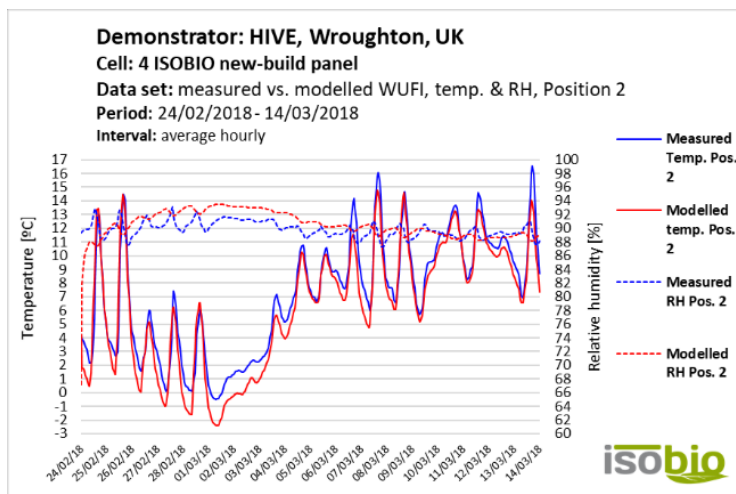

Figure 3: Measured vs. modelled (WUFI) interstitial temperature and relative humidity, position 2 , ISOBIO new-build panel, HIVE

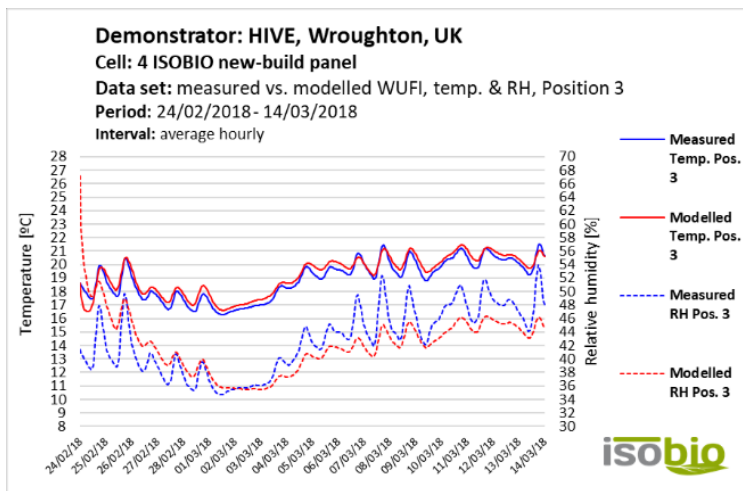

Figure 4: Measured vs. modelled (WUFI) interstitial temperature and relative humidity, position 3 , ISOBIO new-build panel, HIVE

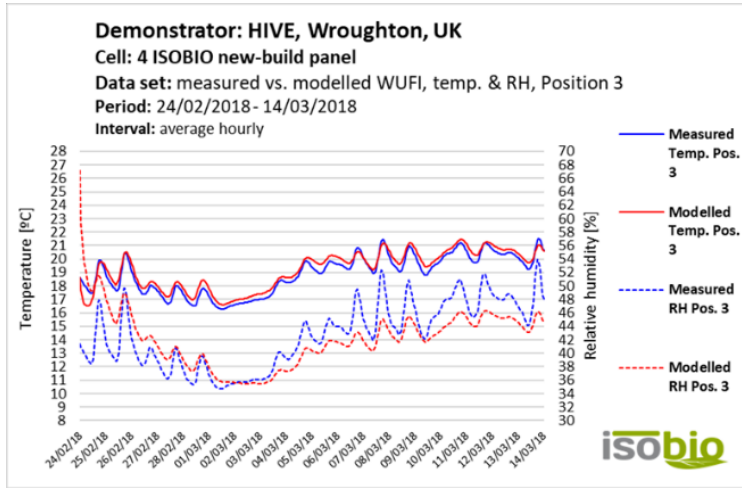

Figure 5: Measured vs. modelled (WUFI) interstitial temperature and relative humidity, position 4, ISOBIO new-build panel, HIVE

\section{Conclusions}

The results of the temperature and RH measured and modelled with WUFI in positions 2,3 and 4 show that the dynamic temperature variations are very well reflected in the model. The short-term variations in relative humidity are not modelled with the same precision in the model, possibly due to the assumption that the equilibrium water content in the materials is instantaneous, when in reality, there is hysteresis [2]. However, the results show a very good correlation between the measured and the calculated values, demonstrating that the materials of biological origin in a composite panel of this type, can contribute to the reduction of energy consumption of a building in its operation phase with a minimum amount of energy embedded in the materials in the manufacturing phase. The results also indicate that moisture transfer within a panel of this kind can be adequately and accurately modelled, providing a means to "stress-test" building elements at design phase and assess their durability under varying moisture conditions.

\section{References}

[1] EN 15026:2007, Hygrothermal performance of building components and building elements - Assessment of moisture transfer by numerical simulation

[2] N. Reuge, F. Collet, S. Pretot, S. Moisette, M. Bart, O. Style, A. Shea, C. Lanos 2019, Hygrothermal transfers through a bio-based multilayered ISOBIO wall - Part I: Validation of a local kinetics model of sorption and simulations of the HIVE demonstrator. Laboratoire de Génie Civil et Génie Mécanique, Axe Ecomatériaux pour la construction, Université de Rennes, 3 rue du Clos Courtel, BP 90422, 35704 Rennes, France. 